\title{
A Case of Severe Hypercalcemia Causing Acute Kidney Injury: An Unusual Presentation of Acute Lymphoblastic Leukemia
}

\author{
Hye Sun Hyun, M.D. ${ }^{2}$ \\ Peong Gang Park, M.D. ${ }^{2}$ \\ Jae Choon Kim, M.D. ${ }^{2}$ \\ Kyun TaekHong, M.D. ${ }^{2}$ \\ Hyoung Jin Kang, M.D., Ph.D. ${ }^{2}$ \\ Kyung Duk Park, M.D., Ph.D. ${ }^{2}$ \\ Hee Young Shin, M.D., Ph.D. ${ }^{2}$ \\ Hee Gyung Kang, M.D., Ph.D. ${ }^{1}$ \\ II Soo Ha, M.D., Ph.D. ${ }^{1}$ \\ Hae Il Cheong, M.D., Ph.D. ${ }^{1}$ \\ Departments of Pediatrics', Seoul \\ National University Children's Hospital, \\ Department of Pediatrics' ${ }^{2}$, Cancer \\ Research Institute, Seoul National \\ University College of Medicine, Seoul, \\ Korea \\ Corresponding author: \\ Hee Gyung Kang, M.D., Ph.D. \\ Department of Pediatrics, Seoul National \\ University Children's Hospital, 101 \\ Deahangno, Jongno-gu, Seoul, 03080, \\ Republic of Korea \\ Tel: +82-2-2072-0658 \\ Fax: +82-2-2072-0274 \\ E-mail:kanghg@snu.ac.kr
}

Received: 24 November 2016

Revised: 3 March 2017

Accepted: 8 March 2017

This is an open-access article distributed under the terms of the Creative Commons Attribution Non-Commercial License (http:// creativecommons.org/licenses/by-nc/4.0/) which permits unrestricted non-commercial use, distribution, and reproduction in any medium, provided the original work is properly cited.

Copyright (C) 2017The Korean Society of Pediatric Nephrology
Severe hypercalcemia is rarely encountered in children, even though serum calcium concentrations above $15-16 \mathrm{mg} / \mathrm{dL}$ could be life-threatening. We present a patient having severe hypercalcemia and azotemia. A 14-year-old boy with no significant past medical history was referred to our hospital with hypercalcemia and azotemia. Laboratory and imaging studies excluded hyperparathyroidism and solid tumor. Other laboratory findings including a peripheral blood profile were unremarkable. His hypercalcemia was not improved with massive hydration, diuretics, or even hemodialysis, but noticeably reversed with administration of calcitonin. A bone marrow biopsy performed to rule out the possibility of hematological malignancy revealed acute lymphoblastic leukemia. His hypercalcemia and azotemia resolved shortly after initiation of induction chemotherapy. Results in this patient indicate that a hematological malignancy could present with severe hypercalcemia even though blast cells have not appeared in the peripheral blood. Therefore, extensive evaluation to determine the cause of hypercalcemia is necessary. Additionally, appropriate treatment, viz., hydration or administration of calcitonin is important to prevent complications of severe hypercalcemia, including renal failure and nephrocalcinosis.

Key words: Hypercalcemia, Acute kidney injury, Azotemia, Leukemia

\section{Introduction}

Severe hypercalcemia is anuncommon problem in children. It is defined as serum calcium (Ca) concentration higher than $12 \mathrm{mg} / \mathrm{dL}$ and is often associated with nonspecific symptoms such as lethargy, depression, anorexia, nausea, vomiting, polyuria and polydipsia. Patients with serum Ca concentrations $>15 \mathrm{mg} / \mathrm{dL}$ can develop renal failure or cardiovascular abnormalities with arrhythmias and coma. Most of the Ca in the body is stored in the bone, and serum Ca levels are regulated mainly by parathyroid hormone (PTH), vitamin $\mathrm{D}$, and calcitonin via bony uptake of $\mathrm{Ca}$ (increased by $\mathrm{PTH}$ and vitamin $\mathrm{D}$, decreased by calcitonin) or resorption of the bone, and renal $\mathrm{Ca}$ reabsorption (increased by PTH, decreased by calcitonin) along with intestinal uptake of $\mathrm{Ca}$ (vitamin D). Therefore when there is hypercalcemia, impairment of bone uptake of the $\mathrm{Ca}$, an increase inbone resorption or impairment of renal 
handling of Ca should be suspected ${ }^{1,2)}$. The most common cause of hypercalcemia is primary hyperparathyroidism in the outpatient clinic and malignancy in hospitalized patients $^{3,4)}$.

Malignancy-associated hypercalcemia can be attributed to three mechanisms; osteolysis from direct invasion of the skeleton by tumor cells, increased osteoclastic bone resorption via tumor production of circulating (humoral) factors, and absorptive hypercalcemia from excessive vitamin $\mathrm{D}$ activation by the neoplasm ${ }^{5,6)}$. While the incidence of malignancy-associated hypercalcemia is about $10-20 \%$ in adults, hypercalcemia is rare in pediatric cancer patients with incidence less than $1 \%$. Malignancy-associated hypercalcemia in children has been reported with rhabdomyocarcoma, leukemia, lymphoma, multiple myeloma, neuroblastoma, hepatocellular carcinoma, and brain tumors. In pediatric acute lymphoblastic leukemia (ALL), hypercalcemia has been reported as the initial manifestation of the malignancy, before the appearance of blasts in the peripheral blood smear ${ }^{7}$. We reported a case of acute leukemia, where the initial presentation was markedly elevated serum Ca levels and acute renal injury.

\section{Case report}

A 14-year- old boy was referred to our hospital with hypercalcemia and azotemia. For last three months, the patient had complained of fatigue, headache, polyuria and polydipsia, which had gradually worsened. During this period, the patient had lost $9 \mathrm{~kg}$ of body weight. On physical examination, his height was $177 \mathrm{~cm}$ ( $>97$ percentiles) and his body weight was $54 \mathrm{~kg}$ (25-50 percentiles). His blood pressure was $133 / 67 \mathrm{mmHg}$, pulse rate 186 per minute, respiratory rate 20 per minute, and body temperature $36.3^{\circ} \mathrm{C}$. The patient was lethargic and he showed pale conjunctivae without lymphadenopathy or hepatosplenomegaly. On mental status examination, he was very irritable and uncooperative while his orientation was intact. Initial laboratory evaluation revealed severe hypercalcemia $(\mathrm{Ca}, 16.5 \mathrm{mg} / \mathrm{dL}$; ionized Ca, $1.93 \mathrm{mmol} / \mathrm{dL}$ ), azotemia (BUN, $39 \mathrm{mg} / \mathrm{dL}$; creatinine, $2.05 \mathrm{mg} / \mathrm{dL}$ ) and mild pancytopenia (white blood

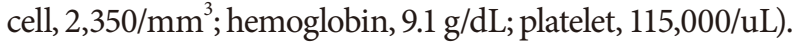
Serum phosphrous level was $4.9 \mathrm{mg} / \mathrm{dL}$ and 25 -hydroxy- vitamin D level was $15.9 \mathrm{ng} / \mathrm{mL}$. PTH level $(<5 \mathrm{pg} / \mathrm{mL})$ was adequately suppressed and Parathyroid hormone-related peptide $(\mathrm{PTHrP})$ was not elevated $(<1.1 \mathrm{pmol} / \mathrm{L}$, reference level; $<1.1 \mathrm{pmol} / \mathrm{L})$. Laboratory data shown in table 1 . On peripheral blood smear, nonspecific findings were reported except mild leukopenia and thrombocytopenia. Chest radiograph was normal. In abdominal ultrasonography, no remarkable findings were observed in abdominal organs including bothkidneys. Despite severe hypercalcemia, there were no significant electrocardiograhic changes. Bone X-ray showed rarefaction along the metaphyseal line suggesting osteopenia.

He was treated with massive intravenous normal saline hydration of $200 \mathrm{~mL}$ per hour and furosemide. He had an adequate urine output $(4.5 \mathrm{cc} / \mathrm{kg} / \mathrm{hr})$. After 12 hours of treatment, serum ionized Ca level was stillelevated (1.87 $\mathrm{mmol} / \mathrm{L}$ ). Hemodialysis was performed using a low-Ca dialysate to relieve hypercalcemia. However, serum $\mathrm{Ca}$ level did not decrease and surged up to $18.0 \mathrm{mg} / \mathrm{dL}$. On the fifth day of hospitalization, intravenous calcitonin (2 IU/ $\mathrm{kg} /$ dose, every 12 hours) was administered, which reduced Ca levels progressively (Fig. 1). His irritability markedly improved with stabilization of Ca level and his azotemia was also ameliorated. Imaging evaluation revealed increased

\begin{tabular}{lcc}
\multicolumn{3}{l}{ Table 1. Laboratory Findings on Hospitalization } \\
\hline Laboratory test & Result & Reference value \\
\hline WBC $\left(\mathrm{mm}^{3}\right)$ & 2,350 & $4,000-13,000$ \\
Hemoglobin (g/dL) & 9.1 & $13-17$ \\
Platelet ( $\left.\times 10^{3} / \mu \mathrm{L}\right)$ & 115 & $130-400$ \\
BUN (mg/dL) & 39 & $10-26$ \\
Serum creatinine (mg/dL) & 2.05 & $0.6-1.4$ \\
Estimated GFR (Schwartz formula) & 35.66 & \\
& $\mathrm{~mL} / \mathrm{min} / 1.73 \mathrm{~m}^{2}$ & \\
Uric acid (mg/dL) & 17 & $3-7$ \\
Alkaline phosphatase (IU/L) & 118 \\
Ferritin (ng/mL) & 421.15 & $60-300$ \\
Lactate dehydrogenase (IU/L) & 140 & $21.8-274.7$ \\
Calcium (mg/dL) & 16.5 & $110-225$ \\
lonized calcium (mmol/L) & 1.93 & $8.8-10.5$ \\
25 hydroxyvitamin D (ng/mL) & 15.9 & $9-37.6$ \\
1,25- hydroxyvitamin D (pg/mL) & 21.2 & $15-60$ \\
Parathyroid hormone (pg/mL) & $<5$ & $10-65$ \\
PTHrP (pmol/L) & $<1.1$ & $0-1.1$ \\
FreeT4 (ng/dL) & 1.08 & $0.7-1.48$ \\
\hline Abbreviations: WBC, white blood cells; BUN, blood urea nitrogen; PTHrP, \\
parathyroid hormone-related peptide. & &
\end{tabular}




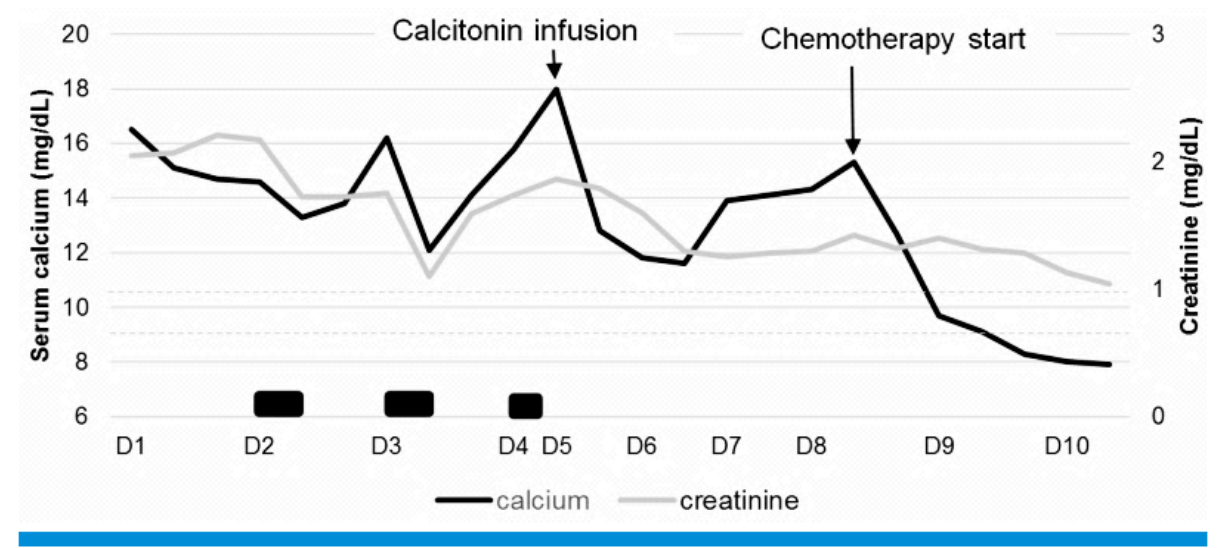

Fig. 1. Serum calcium levels during hospitalization: black bars, hemodialysis; dotted line, serum calcium reference value.

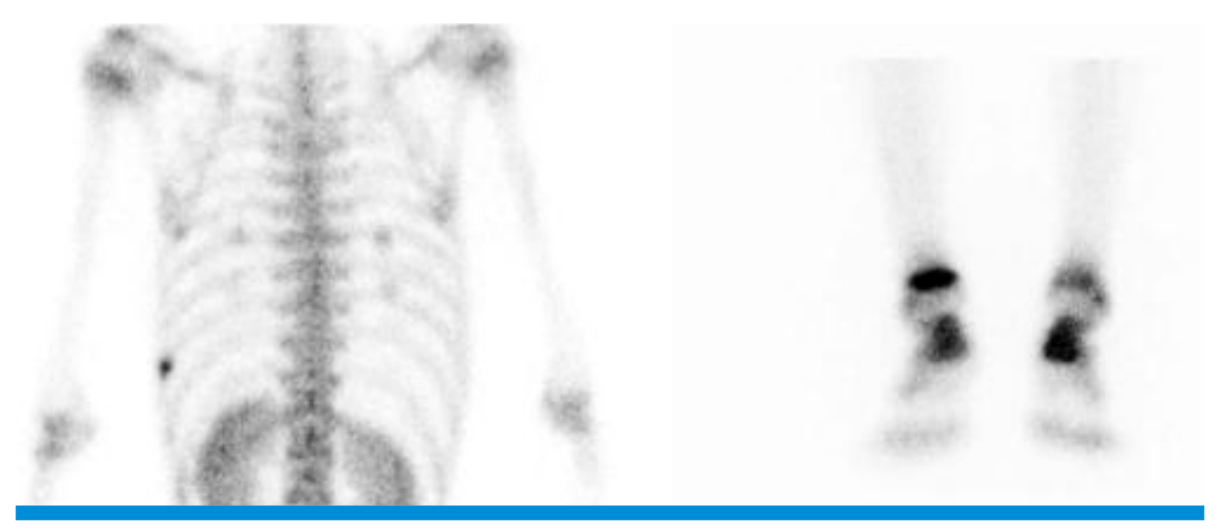

Fig. 2. Bone scan findings: Increased uptake in the lateral arch of left ninth rib, with blunting growth palate in distal right tibia.

uptake in the left 9th rib and right distal tibia on bone scan (Fig. 2) and focal cortical discontinuity at the left 9 th rib on chest CT. Abdominal CT and brain MRI were unremarkable. On 6th day, bone marrow aspiration and biopsy were performed and bone marrow smear revealed acute lymphoblastic leukemia (ALL). Leukemia marker study was also consistent with early precursor B cell type ALL. On the eighth day of hospitalization, induction chemotherapy for ALL was started. His hypercalcemia and azotemia were completely resolved on the third day of chemotherapy.

\section{Discussion}

Here we report a case of severe hypercalcemia accompanying azotemia as initial manifestation of ALL. Commonly, increase in bone resorption leads to hypercalcemia, primarily from hyperparathyroidism and malignancy ${ }^{1,2)}$.
Our case had appropriately suppressed PTH levels, indicating that his hypercalcemia was not PTH-dependent. Therefore, other causes such as malignancy should be suspected, and bone imaging studies for malignancy, bone marrow examination, PTHrP measurement were done. PTHrP is the most commonly identified humoral factor that causes hypercalcemia of malignancy, accounting for that approximately $80 \%$ of malignancy-associated hypercalcemia is due to the effect of $\mathrm{PTHrP}^{4,8)}$. However, our patient had a normal PTHrP level suggesting that osteolytic factors other than PTHrP might lead to hypercalemia, since eventually the patient was diagnosed with malignacy, and chemotherapy targeting leukemia of this case resolved his hypercalcemia along with hypercalcemic symptoms. At presentation, our case had osteopenia, therefore, osteolysis from direct invasion by leukemic cells might be the primary cause of hypercalcemia in this case, rather than humoral factor. The first symptoms of leukemia are usually non- 
specific. Bone pain, arthritis and limping can occur in leukemia children without blats on peripheral blood. It can lead to delayed diagnosis.

Our case also showed mild azotemia along with polydipsia and polyuria (3 L/day) at presentation as a symptom of severe hypercalcemia. Polyuria by hypercalcemia results from suppression of aquaporin-2 at the apical plasma membrane of the collecting duct and resorption of sodium and chloride in the loop of Henle via Ca sensing receptor of the kidney, reducing urinary concentrating ability ${ }^{9,10}$. Thus, patients with hypercalcemia are usually volume-depleted, which might lead to a reduction in the glomerular filtration rate (GFR) and Ca clearance.Therefore, the initial goal of therapy is restoration of extracelluar fluid volume and GFR, with $0.9 \%$ saline by intravenous at $200-500 \mathrm{~mL}$ per hour ${ }^{5)}$. In our case, initial hydration was not effective, partially because loop diuretics was also administered along with hydration. Although loop diuretics can ameliorate mild hypercalciuria via increased Ca loss through tubule, it can cause dehydration, leading to a decline in GFR and the filtered load of $\mathrm{Ca}$. Thus, loop diuretics should be administered after full hydration has been achieved.

To ameliorate severe hypercalcemia and azotemia, hemodialysis was applied in this case. However, removing serum Ca using dialysis was transient, insufficient effect; while dialysis using low-Ca dialysate is a reasonable option for patients with acute hypercalcemia and significant acute kidney injury, dialysis is not a fundamental therapy in a setting of ongoing resorption of bone ${ }^{11)}$. Rapid reduction in bone resorption can be achieved by calcitonin, inhibiting osteoclast bone resorption and increasing urinary excretion of $\mathrm{Ca}$, resulting in reduction of serum Ca levels within six hours after dosing, as shown in our case (Fig. 1). However, the effect of calcitonin is transient, with a mean duration of effect of from two to 4 days $^{122}$. Therefore, either longacting therapy such as bisphosphonates or elimination of primary cause of hypercalcemia, namely ALL for our case, is indicated along with calcitonin. After the confirmation of ALL, our patient was treated with chemotherapy, andhigh-dose corticosteroid. Hypercalcemia was completely resolved, and renal function was also normalized. Corticosteroids are known to inhibit 1a-hydroxylase conversion of 25-hydroxyvitamin D to calcitrio ${ }^{15)}$, therefore,especially effective in hypercalcemia associated with vitamin $\mathrm{D}$ excess. On the other hand, bisphosphonates, a common treatment agent of malignancy-associated hypercalcemia, act by binding to Ca phosphate and inhibiting osteoclast activity, requiring two to four days for achieving significant effect ${ }^{13,14)}$. In addition, bisphosphonates are eliminated unchanged by renal excretion and have potential to induce glomerulosclerosis, physicians are reluctant to use bisphosphonates in patients with renal impairment, and their dosing must be adjusted for impaired renal function to avoid toxicity ${ }^{15)}$. In our case, bisphosphonates were considered but eventually not necessary.

We report one patient with ALL, where severe hypercalcemia associated with acute renal failure was the unusual presentation.

\section{Conflicts of interest}

No potential conflict of interest relevant to this article was reported.

\section{Acknowledgement}

This study was supported by a grant (HI12C0014) from the Korean Health Technology Research \&Development Project, Ministry of Health \& Welfare, Republic of Korea.

\section{References}

1. Mundy GR, Guise Ta. Hormonal control of calcium homeostasis. Clin Chem 1999:45:1347-52.

2. Ravi C, Assunta A, Disorders of calcium homeostasis. In; Elzouki AY,Harfi HA, Nazer H, William OH, Stapleton FB, Whitley RJ, editors, Textbook of Clinical Pediatrics. 2nd ed. NewYork: Springer, 2012; 3611-6.

3. Makras P, Papapoulos SE. Medical treatment of hypercalcaemia. Hormones 2009;8:83-95.

4. Stewart AF. Hypercalcemia associated with cancer. N Engl J Med 2005;352:373-9.

5. Rosner MH, Dalkin AC. Onco-nephrology: The pathophysiology and treatment of malignancy-associated hypercalcemia. Clin J Am Soc Nephrol 2012;7:1722-9.

6. Shu ST, Dirksen WP, Weibaecher KN, Rosol TJ. Mechanisms of Humoral Hypercalcemia of Malignancy in Leukemia/Lymphoma. 
In; olga B, Sinia D, kimberly JP, editors. T-cell Leukemia. 3rd ed. Croatia: InTech, 2002;181-94.

7. McKay C, Furman WL. Hypercalcemia complicating childhood malignancies. Cancer 1993;72:256-60.

8. Takami H. Hypercalcemic crisis. Textb Endocr Surg 2005:543-8.

9. Hasler U, Leroy V, Martin PY, Feraille E. Aquaporin-2 abundance in the renal collecting duct: new insights from cultured cell models. AJP Ren Physiol 2009;297:F10-8.

10. Riccardi D, Brown EM. Physiology and pathophysiology of the calcium-sensing receptor in the kidney. Am J Physiol Ren Physiol 2010;298:F485-99.

11. Argilés a, Kerr PG, Canaud BJM, Flavier JL, Charles Mion. Calcium kinetics and the long-term effects of lowering dialysate calcium concentration. Kidney Int 1993;43:630-40.

12. Wisneski LA, Croom WP, Silva OL, Becker KL. Salmon calcitonin in hypercalcemia. Clin Pharmacol Ther 1978;24:219-22.

13. Davies JH, Shaw NJ. Investigation and management of hypercalcaemia in children. Arch Dis Child 2012;97:533-8.

14. Rogers MJ, Gordon S, Benford HL, Coxon FP, Luckman SP, Monkkonen J, et al. Cellular and molecular mechanisms of action of bisphosphonates. Cancer 2000;88:2961-78.

15. Toussaint ND, Elder GJ, Kerr PG. Bisphosphonates in chronic kidney disease; balancing potential benefits and adverse effects on bone and soft tissue. Clin J Am Soc Nephrol 2009;4:221-33. 